\title{
CASCADED Z-SOURCE ISOLATED DC-DC CONVERTER WITH PWM SHOOT THROUGH CONTROL METHODS
}

\author{
Nimrah Saeed \\ Department of Electrical Engineering \\ Shanghai Jiao Tong University, Shanghai, China \\ Huma Hafeez \\ Department of Mechatronics Engineering \\ Shandong University, Jinan, China
}

\author{
Anas ibrar, \\ Department of Electrical Engineering \\ University of Wah, Wah Cantt, Pakistan \\ Lubna Majeed \\ Department of Electrical Engineering \\ HITEC University, Taxila, Pakistan
}

\begin{abstract}
In this paper a novel topology named Cascaded Z-source Isolated DC-DC Converter (CZIDC) is proposed. This topology inherits advantages of Dual Active Bridge (DAB) as well as Z-source impedance network. To describe operating principle three different PWM control methods are used to insert shoot through state in CZIDC. Finally, performance is investigated through comparative analysis of experimental results and conclusion is drawn.
\end{abstract}

Keywords - CZIBDC, DAB, DC-DC converter, impedance network, shoot through state.

\section{INTRODUCTION}

Due to increasing power consumption, importance of renewable energy sources is enhancing day by day. The rate at which demand for electrical energy is rising, limits the installation plus planning of enormous power plants, eventuating in distributed power generation and energy sources. To minimize the high cost of sources large efforts has been made for development of power conditioning units to serve as an interface amid source and grid. Power available for renewable energy sources is dependent on various factors like intensity of sunlight or power of wind etc. Consequently, an effective energy management is required for storage of energy. Nowadays, different types of energy storages are available and few under development. Ultra-capacitor technology and electrochemical batteries are very reliable and fast growing technologies $[1,2]$. However, power electronic equipment are usually used to convert energy from storage or source. VSI or CSI are most famous topologies for this purpose but these converters face many challenges due to limited output voltage range.

Dual active bridge (DAB) is another promising topology for high power DC-DC converters. It is a bidirectional converter with a frequency transformer which provide galvanic isolation between two active bridges [3, 4]. Still DAB topology has numerous confines because of rapid increment in innovations as design and implementation of high frequency transformer is not easy so the alternate way was introduced in 2012, Z-source impedance network (ZSN) is combined with DAB to improve its efficiency.Although, voltage gain can further be increased by cascading multiple ZSNs together.

The most direct and simplest way of cascading networks is connecting them in series as depicted in Fig.1. In direct cascading, two or more identical copies of impedance networks are connected in series and their input voltages are also added accordingly. So, the AC voltage gain remains unaffected since output voltages of impedance networks yields an overall greater DC-link voltage. Thus, this topology is not a promising strategy considering that it does no longer introduce any new potential to the circuit. Input and output voltage of direct cascading network can be calculated as

$$
\begin{gathered}
v_{i}=\frac{1}{1-2 \frac{T_{0}}{T}} V_{d c_{-} T o t} \\
v_{0}=\frac{0.5 M}{1-2 \frac{T_{0}}{T}} V_{d c_{-} T o t}
\end{gathered}
$$

Where $v_{i}$ is peak dc link voltage, $v_{0}$ is output voltage, $V_{d c_{-} T o t}$ represents all the dc source voltages used in direct cascading impedance network. $\mathrm{M}$ is stated as modulation index and $\frac{T_{0}}{T}$ is shoot through duration. 


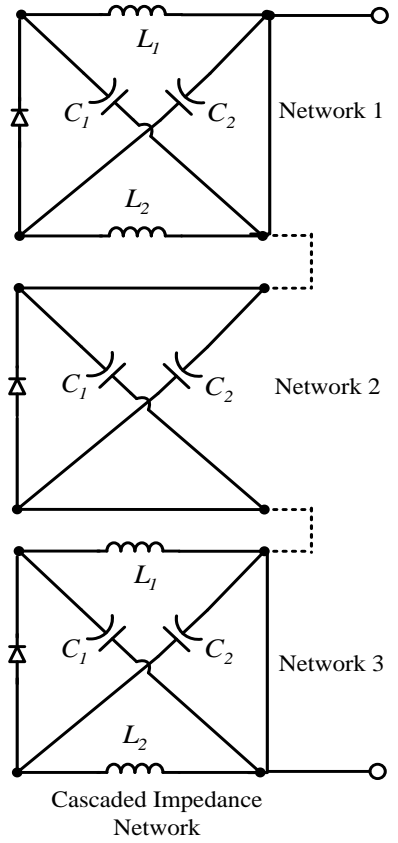

Fig.1. Direct Cascading

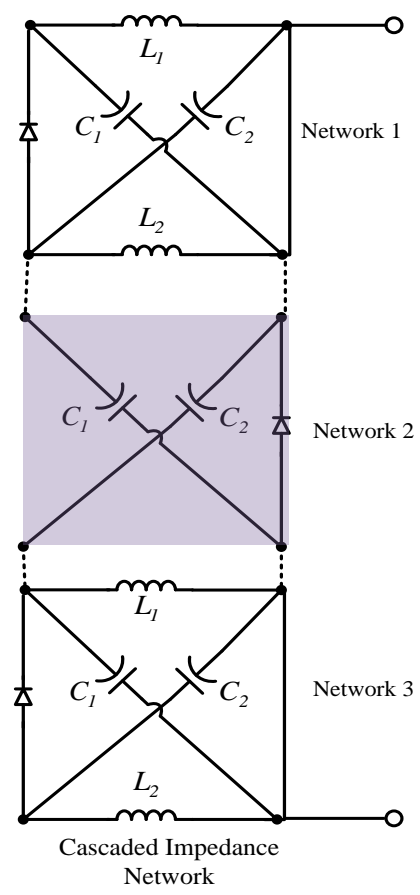

Fig.2. Alternate Cascading

Another methodology is alternate cascading method, in which network 2 is initially flipped horizontally in respect of network 1 and formerly joined with the prior and so on, as a result same directions of current and voltages are obtained in upper and lower inductive branch of network [5] as revealed in Fig.2.

$$
\begin{gathered}
v_{i}=\frac{2}{1-3 \frac{T_{0}}{T}} V_{d c_{-} T o t} \\
v_{0}=\frac{M}{1-3 \frac{T_{0}}{T}} V_{d c_{-} T o t}
\end{gathered}
$$

Eq.3 and 4, represents peak dc and output voltage of alternate cascading method.

From above equations it is clear that voltage gain of alternate cascading method is greater than direct cascading. When producing the voltage gain, dc link voltage ratio versus Z-source duty ratio graph is shown in Fig.3

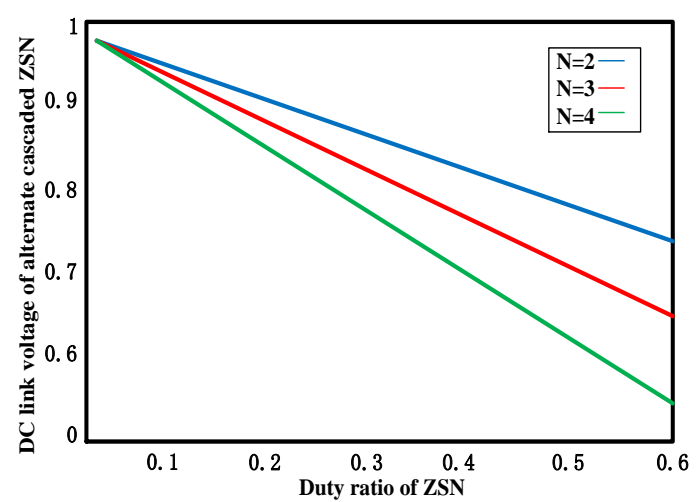

Fig.3. Voltage ratio versus duty ratio graph of alternate cascading method, $\mathrm{N}=$ number of cascaded levels.

This paper presents a novel configuration named Cascaded Z-source Isolated DC-DC Converter (CZIDC), in which alternate cascaded topology is combined with DAB. Shoot through state is inserted in this topology through three different control methods i.e. simple boost control, maximum boost control and space vector modulation boost control methods.

The rest of paper is divided into four sections. Basic topology of CZIDC is presented in section II . Simulation and Results will be defined in section III and Conclusion is drawn in section IV.

\section{CASCADED Z-SOURCE ISOLATED DC TO DC CONVERTER}

Fig.5 shows the proposed topology of CZBDC, which consists of a cascaded Z-source impedance network, a high frequency transformer and two $\mathrm{H}$-bridges are placed on primary and secondary side of transformer. The phenomenon that power is transferred from left to right side is called forward power flow if not then, reverse power flow. This paper only examines the forward power flow. 


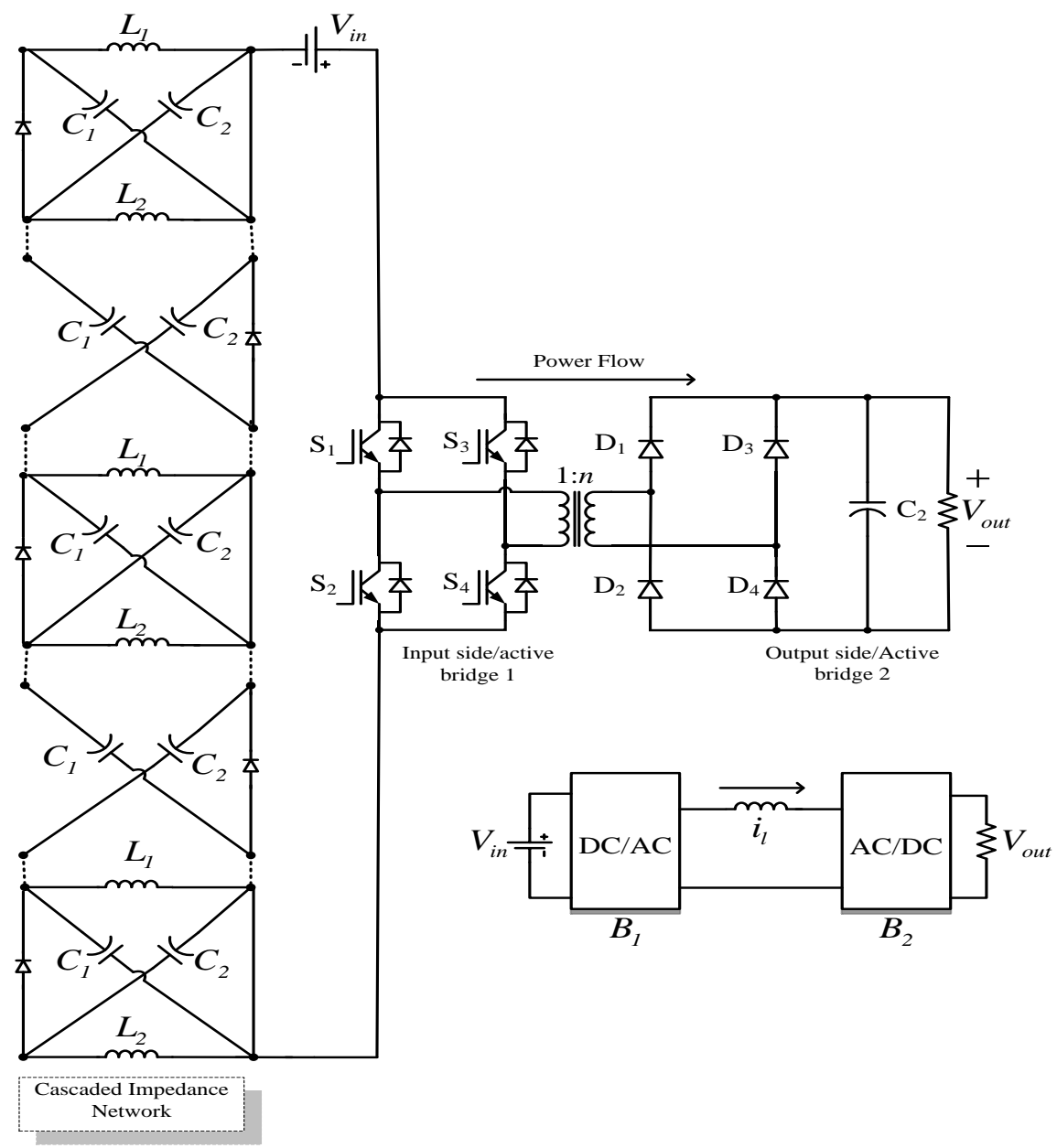

Fig.5. Cascaded Z-source isolated DC-DC Converter

In the proposed topology, HVDC is first regulated by impedance network and then transferred to H-bridge 1. Here the cross connected switch pairs $\left(S_{1}, S_{4}\right)$ and $\left(S_{2}, S_{3}\right)$ switch in turn to transform voltage from $\mathrm{DC}$ to $\mathrm{AC}$ and transformer transfers the AC voltage from primary side to secondary side. Diodes $\left(D_{1}-D_{4}\right)$ on secondary side of transformer work as a rectifier to transform $\mathrm{AC}$ voltage into $\mathrm{DC}$ again. Fig.6. demonstrations the equivalent circuit of topology.

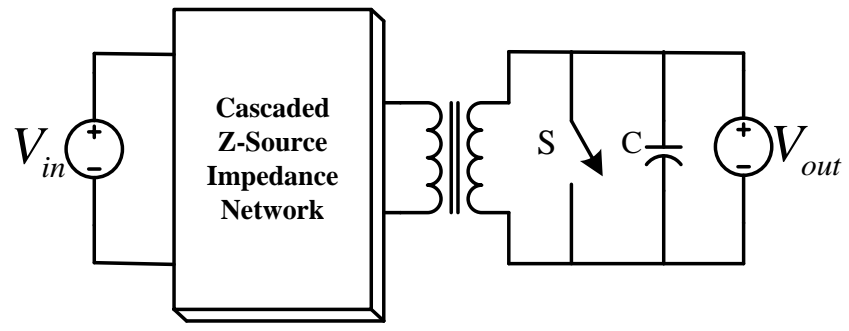

\section{A. PWM Shoot Through Control Methods}

Z-source inverter has extensive variety of procurable voltage (between 0 and $\infty$ ) because of its unique feature of buck-boost capability.

Circuit diagram of Z-source inverter in shoot through and non-shoot through states are presented in Fig.7. During shoot through state, a switch is used to shorten output terminals of network, which reverse- bias the diode in impedance network. During non-shoot through state, all diodes are turned ON and stored energy of capacitors and inductors is conducted to the load. DC link voltage and capacitor voltage during steady state can be expressed as [6]

$$
\begin{gathered}
v_{i}=\frac{v_{\text {in }}}{1-2 D_{0}} \\
v_{c}=\frac{v_{\text {in }}}{1-D_{0}}
\end{gathered}
$$

Fig.6. Equivalent circuit 
Where, $\quad D_{0}=\frac{T_{0}}{T_{s}}$

$T_{0}$, is shoot through time, $T_{s}$ is switching period and $D_{0}$ represents shoot through duty ratio. To insert shoot through state in ZSN following four shoot through control methods have been proposed.
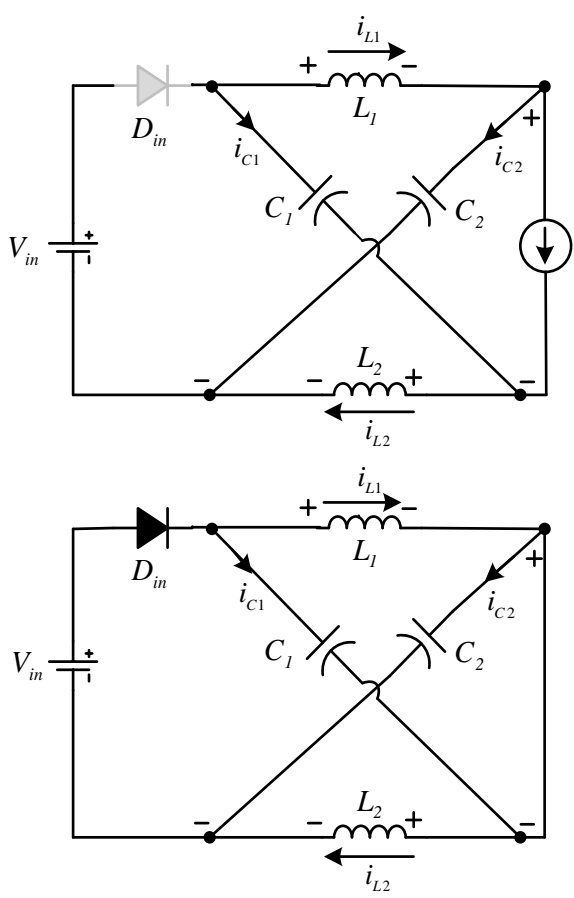

Fig.7. Shoot-through and Non-shoot through state of ZSN

\section{1) Simple Boost Shoot Through Control Method}

In this methodology, to generate active and non-active state, carrier wave is compared with a reference line and sine wave as shown in Fig.8. This method uses two straight lines greater than or equivalent to reference signal to control shoot through duty ratio (i.e. upper line $V_{p}$ and lower line $V_{n}$ ). The circuit turns in shoot through state when triangular carrier waveform is either larger than $V_{p}$ or lesser than $V_{n}[6,7]$. Shoot through duty ratio and voltage gain for simple boost through control system can be expressed as

$$
\begin{gathered}
D=1-M \\
G=\frac{M}{2 M-1}
\end{gathered}
$$

Where, $\mathrm{M}$ is stated as modulation index i.e. ratio of amplitude of modulation waveform and carrier waveform, D represents duty ratio and $G$ is voltage gain for this control system.

\section{2) Maximum Boost Shoot Through Control Method}

In maximum boost shoot through control method, there are only two states i.e. active state and shoot through state (no non-active state). These states can be attained when carrier wave is compared with sine wave, as presented in Fig.9. When carrier wave is greater than the sine wave, the circuit is in shoot through state and when carrier wave is lesser than sine wave it will behave like normal sine pulse width modulation. Maximum voltage gain can be attained from this control system [8]. Eq.9 represents the boost factor B, for maximum boost control system.

$$
B=\frac{\pi}{3 \sqrt{3} M-\pi}
$$

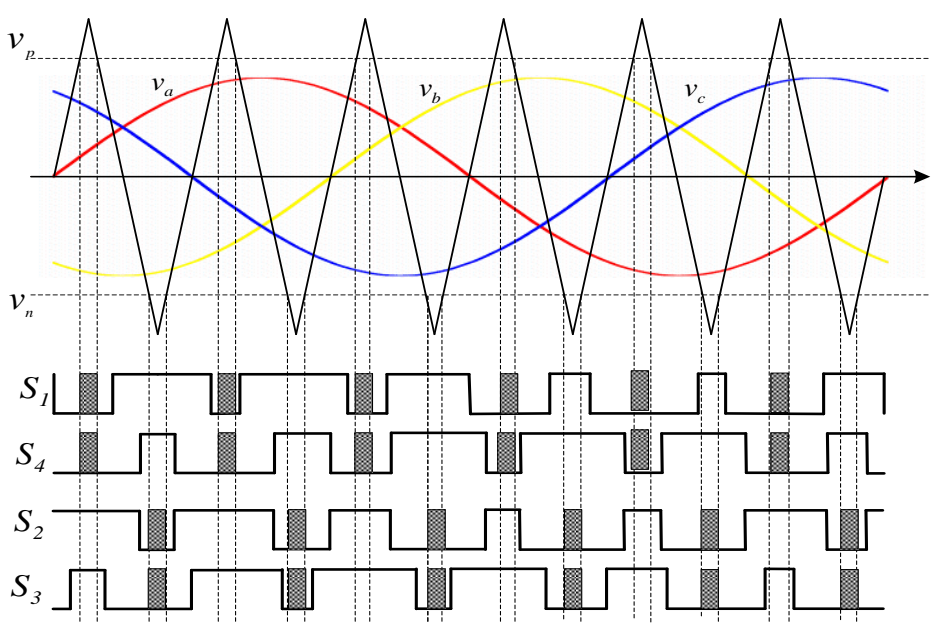

Fig.8.Simple control method waveform

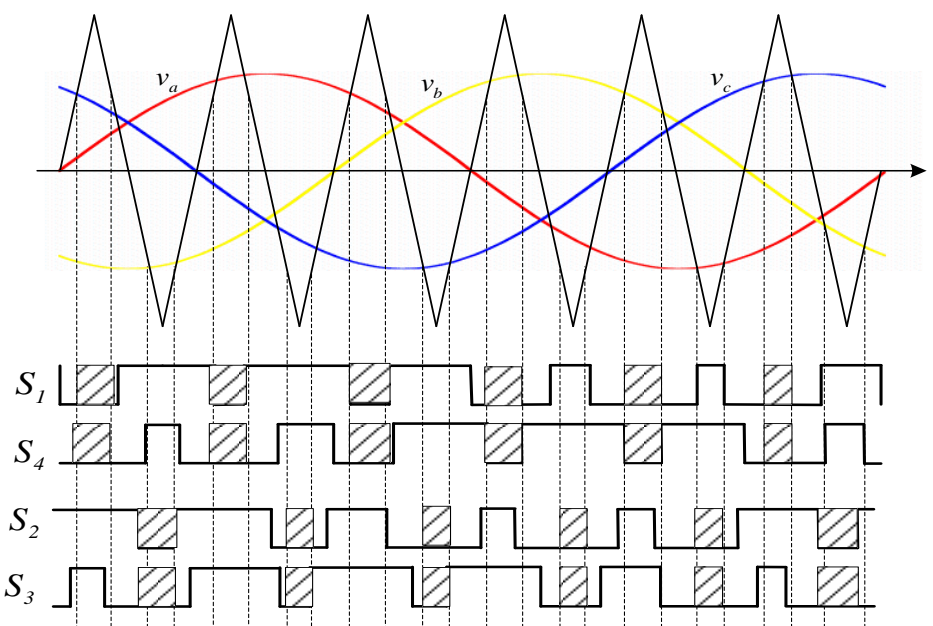

Fig.9. Maximum control method waveform

\section{3) Space Vector Modulation Control Method}

No separate modulator is needed in SVPWM technique. The voltage reference provided in SVPWM method is sampled at fixed high frequency and preceded as a whole. In this 


\section{International Journal of Engineering Applied Sciences and Technology, 2019 \\ Vol. 4, Issue 2, ISSN No. 2455-2143, Pages 53-58 \\ Published Online June 2019 in IJEAST (http://www.ijeast.com)}

method, magnitude and frequency of reference vector control frequency and magnitude of fundamental component. DC bus voltage is utilized in this method causing less harmonic distortion [10-12]. Switching period of SVPWM is shown in Fig.11.

$$
\begin{aligned}
& D=\frac{2 \pi-3 \sqrt{3} M}{2 \pi} \\
& G=\frac{\pi M}{3 \sqrt{3} M-\pi}
\end{aligned}
$$

Duty ratio $\mathrm{D}$ and voltage gain $\mathrm{G}$ are represented in Eq. 10 and 11 respectively.

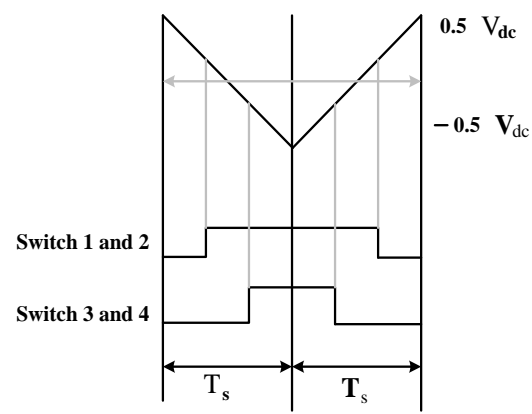

Fig.11. Switching period of SVPWM

\section{Simulations AND Results}

To illustrate the proposed model, CZIDC topology has been tested on MATLAB with above mentioned control strategies. Parameters of impedance network are $L_{1}=L_{2}=5 \times 10^{-3} \mathrm{H}$ and $C_{1}=C_{2}=0.0022 \mathrm{~F}$. All simulations have been done for input voltage of $200 \mathrm{~V}$ and medium frequency of $400 \mathrm{~Hz}$.

Fig.12. shows the DC output of proposed model and Fig.13.shows comparison of all topologies.

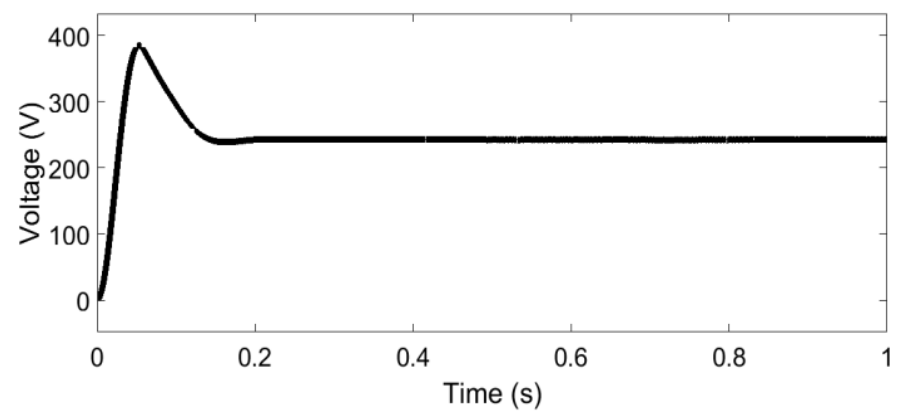

Fig.12 (a) Simple boost control method

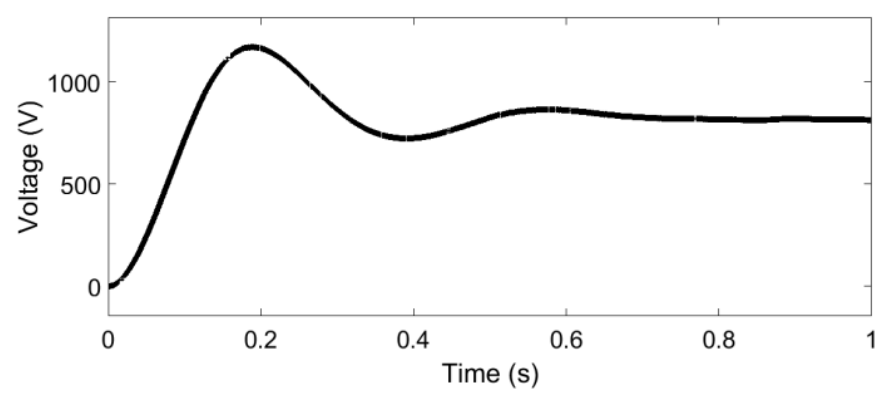

Fig. 12 (b) Maximum boost control method

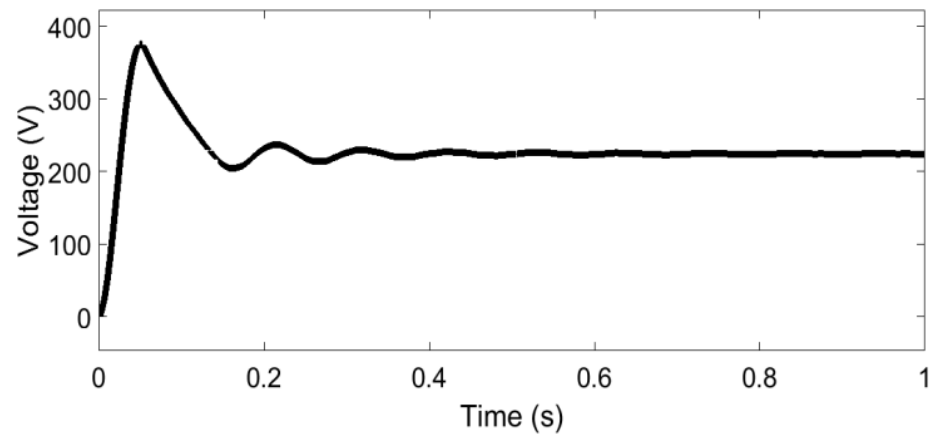

Fig. 12 (c) Space Vector PWM control method

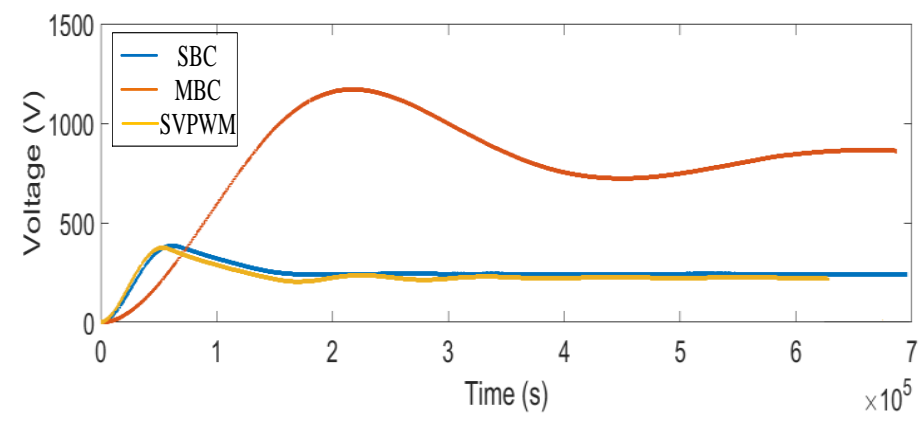

Fig.13. Comparison of all topologies

Fig. 12 (a) predicts that in simple boost control method, stable output DC voltage is obtained is $240 \mathrm{~V}$ while the provided input voltage is $200 \mathrm{~V}$. In this control system, when modulation index is increased, shoot through duty ratio decrease and voltage stress is large on devices. This method is simple and direct, though the resulting voltage stress through switches is comparatively high as some usual zero states are not used. For maximum boost control systems DC output waveform attained is at almost $800 \mathrm{~V}$ as presented in Fig.12 (b). Minimum voltage stress across switches can be attained through this control system. In this control system, shoot through duty ratio and voltage boost are inversely proportional, which means that if voltage boost will upsurge, shoot through duty ratio will be reduced.

For space vector pulse width control systems DC output waveform attained is in between $220 \mathrm{~V}$ to $250 \mathrm{~V}$ as shown in Fig.12(c). In this control system, sequence of switches is arranged in such a manner that only one converter leg is operational during one cycle, in this way less switching 


\section{International Journal of Engineering Applied Sciences and Technology, 2019 \\ Vol. 4, Issue 2, ISSN No. 2455-2143, Pages 53-58 \\ Published Online June 2019 in IJEAST (http://www.ijeast.com)}

frequency is consumed. It is clear from simulation results that this novel topology is very valuable for HVDC applications instead of conventional converters. Comparison of all control systems for the proposed topology shows that maximum boost control system is most suitable as compared to other control systems as maximum DC voltage waveform is attained by using this control system.

\section{CONCLUSION}

CZIDC is a novel DC-DC topology proposed in this paper and different shoot through methods are presented to analyze the best control strategy. Keen observation of simulation results demonstrates that maximum boost control is most suitable for this topology as boosting capability of circuit is maximum with this control system and voltage stress across switches is minimum in this control system because entire zero state is transformed into switching cycle.

\section{REFRENCES}

[1] Rahim O.A, Funato H., and Haruna J. (2015),"Z-source with Voltage Multiplication Inverter for Grid-tie Photovoltaic Applications."IEEE/ Telecommunications Energy Conference (INTELEC), (pp.1-6).

[2] Rabkowski J. (2007), "The bidirectional Z-source Inverter for Energy Storage Application." IEEE/Power Electronics and Applications, (pp.1-10)

[3] Zhu M., Yu K.and Luo F.L. (2010), "Switched Inductor Z-Source Inverter," IEEE Trans. Power Electronics, (pp. $2150-2158)$.

[4] Peng F.Z. (2003), “Z-Source Inverter," IEEE Trans. Industry Applications, (pp.504-510).
[5] Li D., Gao F., Loh P.C., Zhu M. and Blaabjerg F. (2011), "Hybrid-Source Impedance Networks: Layouts and Generalized Cascading Concepts" IEEE Trans. on Power Electronics, (pp. 2028-2040).

[6]Ellabban O., Mierlo J.V., and Lataire P. (2011), "Experimental Study of the Shoot-Through Boost Control Methods for the Z-Source Inverter," $E P E$ Journal, (pp.18-29).

[7] Sivapriyan R. and Umashankar S. (2016), "Comparative Analysis of PWM Controlling Techniques of Single Phase Z-Source Inverter." Indian Journal of Science and Technology, (DOI: 10.17485).

[8] Kumar M.A. and Barai M. (2015), "Performance Analysis of Control and Modulation Methods of Z-source Inverter," IEEE/ Signal Processing, Informatics, Communication and Energy Systems (SPICES), (pp.1-5).

[9] Shen M., Wang J., Joseph A., Peng F.Z., Tolbert L.M., and Adams D.J. (2006), "Constant boost control of the Zsource inverter to minimize current ripple and voltage stress," IEEE Trans. Industrial. Applications, (pp. 770778).

[10] Misha A., Save S. and Sen R. (2014), "Space Vector Pulse

Width Modulation," International Journal of scientific \& engineering research (IJSER).

[11] Khan J.F.,Bhuiyan S.M.A.,Rahman K.M. and Murphy G.V. (2013), "Space vector PWM for a two-phase VSL VSI." International Journal of Electrical Power \& Energy Systems", (pp. 265-277).

[12] Loh P.C., Vilathgamuwa D.M., Lai Y.S., Geok, Chua T. Li Y. (2005), "Pulse-Width Modulation of Z-Source Inverters", IEEE Trans. on power electronics, (pp.1346- 